\title{
Phenotype-dependent alteration of pathways and networks reveals a pure synergistic mechanism for compounds treating mouse cerebral ischemia
}

\author{
Peng-qian WANG ${ }^{1}$, Bing $\mathrm{LI}^{1}$, Jun LIU ${ }^{1}$, Ying-ying ZHANG ${ }^{1}$, Ya-nan $\mathrm{YU}^{1}$, Xiao-xu ZHANG ${ }^{1}$, Ye YUAN ${ }^{1}$, Zhi-li GUO ${ }^{1}$, Hong-li WU $^{1}$, \\ Hai-xia $\mathrm{LI}^{2}$, Hai-xia DANG ${ }^{1}$, Shan-shan GUO ${ }^{1}$, Zhong WANG ${ }^{1, *}$ \\ ${ }^{1}$ Institute of Basic Research in Clinical Medicine, China Academy of Chinese Medical Sciences, Beijing 100700, China; ${ }^{2}$ Guang'anmen \\ Hospital, China Academy of Chinese Medical Sciences, Beijing 100053, China
}

\begin{abstract}
Aim: Our previous studies have showed that ursodeoxycholic acid (UA) and jasminoidin (JA) effectively reduce cerebral infarct volume in mice. In this study we explored the pure synergistic mechanism of these compounds in treatment of mouse cerebral ischemia, which was defined as synergistic actions specific for phenotype variations after excluding interference from ineffective compounds. Methods: Mice with focal cerebral ischemia were treated with UA, JA or a combination JA and UA (JU). Concha margaritifera (CM) was taken as ineffective compound. Cerebral infarct volume of the mice was determined, and the hippocampi were taken for microarray analysis. Particular signaling pathways and biological functions were enriched based on differentially expressed genes, and corresponding networks were constructed through Ingenuity Pathway Analysis.

Results: In phenotype analysis, UA, JA, and JU significantly reduced the ischemic infarct volume with JU being superior to UA or JA alone, while CM was ineffective. As a result, 4 pathways enriched in $\mathrm{CM}$ were excluded. Core pathways in the phenotype-positive groups (UA or JA) were involved in neuronal homeostasis and neuropathology. JU-contributing pathways included all UA-contributing and the majority $(71.7 \%)$ of JA-contributing pathways, and 10 new core pathways whose effects included inflammatory immunity, apoptosis and nervous system development. The functions of JU group included all functions of JA group, the majority (93.1\%) of UA-contributing functions, and 3 new core functions, which focused on physiological system development and function.

Conclusion: The pure synergism between UA and JA underlies 10 new core pathways and 3 new core functions, which are involved in inflammation, immune responses, apoptosis and nervous system development.
\end{abstract}

Keywords: cerebral ischemia; phenotype; ursodeoxycholic acid; jasminoidin; concha margaritifera; pure synergistic mechanism; microarray analysis

Acta Pharmacologica Sinica (2015) 36: 734-747; doi: 10.1038/aps.2014.168; published online 11 May 2015

\section{Introduction}

A great deal of emphasis has been placed on combination therapy for cerebral ischemia, which is thought to be more effective and has fewer adverse effects than single therapies ${ }^{[1,2]}$. Our understanding of the synergistic properties of many current or possible combination therapies has implications for improving therapeutic efficacy and safety ${ }^{[3]}$. Many experimental methods have been proposed to screen favorable drug combinations using disease-relevant phenotypic assays ${ }^{[4]}$. Various models and measures, such as the enhanced Petri-Net (EPN) model, Target Inhibition inference using Maximization and Minimization Averaging (TIMMA), additive syn-

\footnotetext{
* To whom correspondence should be addressed.

E-mail zhonw@vip.sina.com

Received 2014-08-31 Accepted 2014-12-08
}

ergism, Bliss independence, the Chou-Talalay Combination Index, the isobolographic approach, Loewe additivity, and nonlinear blending, have been developed to assess synergistic drug actions ${ }^{[5-14]}$. Considerable research suggests that the synergistic mechanism of drugs is not simply "one target, one pathway". Therefore, it is imperative to turn to network pharmacology by examining the holistic response of phenotyperelated pathways to drug perturbation ${ }^{[15-18]}$. However, there is not a clear methodology for screening the core pathways that mediate phenotype variation during global network rewiring. Ways to exclude interference from compounds that are not responsible for outcomes, particularly when the perturbation is from a mixture, are also not well studied. Additional concerns include what role(s) the negative phenotype compounds (compounds that are not responsible for phenotypic variation) play in the full treatment, whether negative phenotype com- 
pounds affect the core pathway or pure synergism between positive phenotype compounds (compounds contributing to phenotypic variation), and how to investigate the pure synergistic mechanism between positive phenotype ingredients in a mixture. These problems may fundamentally limit the research and design of combination therapies. Thus far, to our knowledge, there is still a lack of research on this topic.

Reverse pharmacology follows the drug-development path from phenotype to target to drug, rather than the classical drug discovery mode. In the reverse pharmacology process, the drug candidates (always effective mixtures) that have known effects on a disease-related phenotype are evaluated for their target-activity, and the active ingredients are extracted. This process may enable more intelligent subsequent screenings of compounds with increased relevant assay readout ${ }^{[19,20]}$ and effectively derive core pathways specific for phenotype variations. Accordingly, reverse pharmacology is an important tool for screening and designing combination therapy.

All drugs were injected into the tail vein $1.5 \mathrm{~h}$ after the induction of focal cerebral ischemia at $2 \mathrm{~mL} / \mathrm{kg}$ body weight for once. Our previous studies have shown that ursodeoxycholic acid (UA) and jasminoidin (JA) can significantly reduce ischemic infarct volume ${ }^{[21-25]}$. In the current study, we further explored the pure synergistic mechanism of these drugs, excluding interference from any negative phenotype compounds. To accomplish this goal, we compared positive phenotype compounds with negative phenotype compounds, identified differentially expressed genes, constructed networks, and analyzed pathway and function alteration using Ingenuity Pathway Analysis system (IPA, QIAGEN Inc, Dusseldorf, Germany).

\section{Materials and methods}

\section{Animal model}

Animal experiments were conducted according to the Prevention of Cruelty to Animals Act of 1986 and NIH guidelines for the care and use of laboratory animals for experimental procedures. The animal use protocols were reviewed and approved by the Ethics Review Committee for Animal Experimentation, China Academy of Chinese Medical Sciences. A focal cerebral ischemia-reperfusion model was induced after mice were anesthetized with $2 \%$ pentobarbital $(4 \mathrm{mg} / \mathrm{kg}$, ip) by middle cerebral artery obstruction, as previously described ${ }^{[26]}$. The middle cerebral artery received an intraluminal filament and was ligated for $1.5 \mathrm{~h}$ and then re-perfused for $24 \mathrm{~h}$. In the sham-operated mice, the external carotid artery (ECA) was surgically prepared for the insertion of the filament, but the filament was not inserted.

\section{Drug administration}

The compounds used, ie, UA, JA and concha margaritifera $(\mathrm{CM})$, were standards provided by the National Institutes for Food and Drug Control, the purity were validated by fingerprint chromatographic methodologies. All compounds were dissolved in $0.9 \% \mathrm{NaCl}$ just before the experiment. All drugs were injected into the tail vein $1.5 \mathrm{~h}$ after the induction of focal cerebral ischemia at $2 \mathrm{~mL} / \mathrm{kg}$ body weight.

A total of 84 male mice (Kunming strain, 3 months old, 38-48 g) were used in this study. In the first experiment, 54 mice were randomly assigned into one of six groups: sham $(0.9 \% \mathrm{NaCl})$; vehicle $(0.9 \% \mathrm{NaCl})$; JA $(25 \mathrm{mg} / \mathrm{mL})$-treated; UA $(7 \mathrm{mg} / \mathrm{mL})$-treated; $\mathrm{CM}(50 \mathrm{mg} / \mathrm{mL})$-treated; and combination-treated (combination of JA and UA at a 1:1 ratio; the total volume is the same as those of the single compound groups). Nine mice in each group were used for infarction volume tests (phenotype-related analysis) to screen the pharmacological effects of the individual compounds. In the second experiment, 30 mice were divided into 6 groups as in the first experiment and subsequently used for microarray analysis (underlying mechanism analysis). Details of this analysis are discussed in our previous studies ${ }^{[21-26]}$.

\section{Phenotype-related screening analysis: calculation of cerebral infarct volume}

Nine mice in each group underwent phenotype-related analysis and were used to calculate the infarct ratio after the $24 \mathrm{~h}$ reperfusion. The brain was removed and cut into five slices in the coronal plane $1,3,5$, and $7 \mathrm{~mm}$ from the prefrontal cortex. The slices were stained with 1\% 2,3,5-triphenyl tetrazolium chloride (TTC) in phosphate buffer $(0.1 \mathrm{~mol} / \mathrm{L}, \mathrm{pH} 7.4)$ for 30 min at $37^{\circ} \mathrm{C}$ in darkness, and then transferred to $10 \%$ formalin. Images of these slices were captured by a digital camera (Color CCD camera TP-6001A, Topica Inc, Tokyo, Japan). The area of the infarction region was calculated using a Pathology Image Analysis System (Topica Inc), and the ratio of the infarction volume to the total slice volume was calculated as described in our previous study ${ }^{[12-26]}$.

\section{RNA extraction and microarray}

The hippocampi of 5 mice in each group were used for underlying mechanism analysis, including RNA isolation and microarray analysis. The cDNA microarray, including 374 cDNA ischemia-related genes, was selected from the Science STKE database. The details of this process are described in our previous studies ${ }^{[21-26]}$.

\section{Micro-array data analysis}

All experimental analyses were performed using the ArrayTrack system (US Food and Drug Administration, Silver Spring, ML, USA). Microarray data analysis was based on the Minimum Information about a Microarray Experiment (MIAME) guidelines and the Micro-array Quality Control (MAQC) project. The results were submitted to the Array Express database. All data were normalized by locally weighted scatter plot smoothing (Lowness) to reduce experimental variability ${ }^{[21-26]}$. One-way analysis of variance and significant analysis of micro-arrays were employed to compare the mean numbers of the altered genes between the vehicle and sham, $\mathrm{CM}$ and vehicle, $\mathrm{UA}$ and $\mathrm{CM}, \mathrm{JA}$ and $\mathrm{CM}$, and JU and $\mathrm{CM}$ groups. To investigate the pure synergistic mechanisms among the effective compounds and exclude any inef- 
fective compound action, we compared positive phenotype groups (groups shown to be effective in reducing cerebral infarct volume, including UA, JA, JU) with negative phenotype groups (groups shown to be ineffective in reducing cerebral infarct volume, including $\mathrm{CM}$ ). The phenotype results are shown below. Genes with a $P$ value $<0.05$ and a $>1.5-$ fold change were selected for further analysis. Additionally, a $>1.5$-fold increase or $<0.5$-fold decrease in the expression levels indicated up- or down-regulation, respectively. A list of significantly differentially expressed genes was uploaded to the IPA system (http://www.ingenuity.com/). A cutoff was set to identify molecules whose expression was significantly differentially regulated; these molecules were known as Network Eligible molecules. Networks of Network Eligible Molecules were then algorithmically generated based on their connectivity. Right-tailed Fisher's exact test was used to calculate a $P$ value that determined the probability that each biological function assigned to that network was due to chance alone. The significance of the association among these genes and the canonical pathways was measured in two ways: (1) the ratio of the number of genes from the data set that map to the pathway divided by the total number of genes that map to the canonical pathway; and (2) Fisher's exact test, which was used to calculate a $P$ value that determined the probability that the association between the genes and the canonical pathway could be explained by chance alone. The level of statistical significance was set at $P<0.05$. Finally, canonical pathways with a $P$ value $<0.05$ and a $>1.5$-fold change were screened out and analyzed ${ }^{[21-26]}$.

\section{Results}

Pharmacological phenotype variation of ischemic infarct volume As described in our previous studies, UA, JA, and JU were effective in reducing the ischemic infarct volume, whereas $\mathrm{CM}$ was ineffective. The infarct volume was reduced further by the combination therapy than by each single compound ${ }^{[21-26]}$ $(P<0.05)$. Thus, we termed the $\mathrm{CM}$ group a negative phenotype group, and the other groups were considered positive phenotype groups.

\section{Altered networks and pathways in vehicle}

According to the IPA analysis, 66 genes were identified as significantly differentially expressed between the vehicle and sham groups (Supplement Table 1). Based on these genes, 2 significant networks were constructed (Figure 1A), and 6 significant canonical pathways (Figure 2A) and 74 biological functions (Figure 3A) were identified.

\section{No-prospective changes of networks and pathways in non-} effective treated group

The IPA analysis identified 30 significantly differentially expressed genes between the CM and vehicle groups. A total of 1 network, 4 canonical pathways (Serotonin Receptor Signaling, Coagulation System, Calcium Signaling, and G-protein Coupled Receptor Signaling), and 39 biological functions were found to be statistically significant (Supplement Table 1). To explore the actions of CM targets, we compared the CM and vehicle contributing pathways and found 2 canonical pathways (Serotonin Receptor Signaling and Calcium Signaling), accounting for $50 \%$ of the total pathways, and 35 enriched functions, accounting for $89.7 \%$ of the total functions that overlapped between the CM and vehicle groups (Figure 4).

\section{Single effective treated groups compared to non-effective group}

Ten and twenty-two significantly differentially expressed genes were identified in the UA and JA groups, respectively, compared with the CM group. One statistically significant network was constructed in both the UA and JA groups. There were 1 and 59 canonical pathways, and 29 and 53 biological functions were enriched in the UA and JA groups, respectively (Supplement Table 1, Figure 1-3). Because of the different phenotypic effects of UA, JA and CM, we eliminated the pathways and functions that overlapped with the $\mathrm{CM}$ or vehicle group from the UA or JA group to further uncover the underlying core pathways that exert pharmacological effects. After these pathways and functions were removed, 1 and 57 core pathways remained, 1 and 1 core function remained in the UA and JA groups, respectively (Table 1).

Table 1. Core pathways and functions in each group.

\begin{tabular}{llrrrr}
\hline & UA & JA & JU & $\begin{array}{c}\text { New } \\
\text { emerging }\end{array}$ \\
\hline Pathways & & & & 12 \\
& Total & 1 & 59 & 46 & 12 \\
& Overlapping with CM & 0 & 1 & 3 & 2 \\
& Overlapping with Vehicle & 0 & 2 & 2 & 0 \\
& Core pathways & 1 & 57 & 42 & 10 \\
& Functions & & & & \\
& Total & 29 & 53 & 73 & 14 \\
& Overlapping with CM & 16 & 32 & 37 & 3 \\
& Overlapping with Vehicle & 27 & 50 & 65 & 10 \\
& Core functions & 1 & 1 & 4 & 3 \\
\hline
\end{tabular}

According to the differentially expressed genes identified by IPA, the enriched biological functions can be divided largely into the following 3 categories: diseases and disorders, molecular and cellular functions, and physiological system development and function. The classifications of the functions in each group are shown in Figure 5.

\section{Pure pharmacological synergism of combination treatment}

The JU group had 29 differentially expressed genes, 1 network, 46 pathways, and 73 functions compared with the CM group (Supplementary Table 1). In the JU group, there were 42 core pathways and 4 functions (Table 1). A synergistic effect indicates that the efficacy of the combination of drugs is greater than the sum of the efficacies of the individual drugs when administered separately ${ }^{[14]}$. We created a list of enriched pathways and functions to evaluate the synergism.

When JA was combined with UA, all of UA contributing 


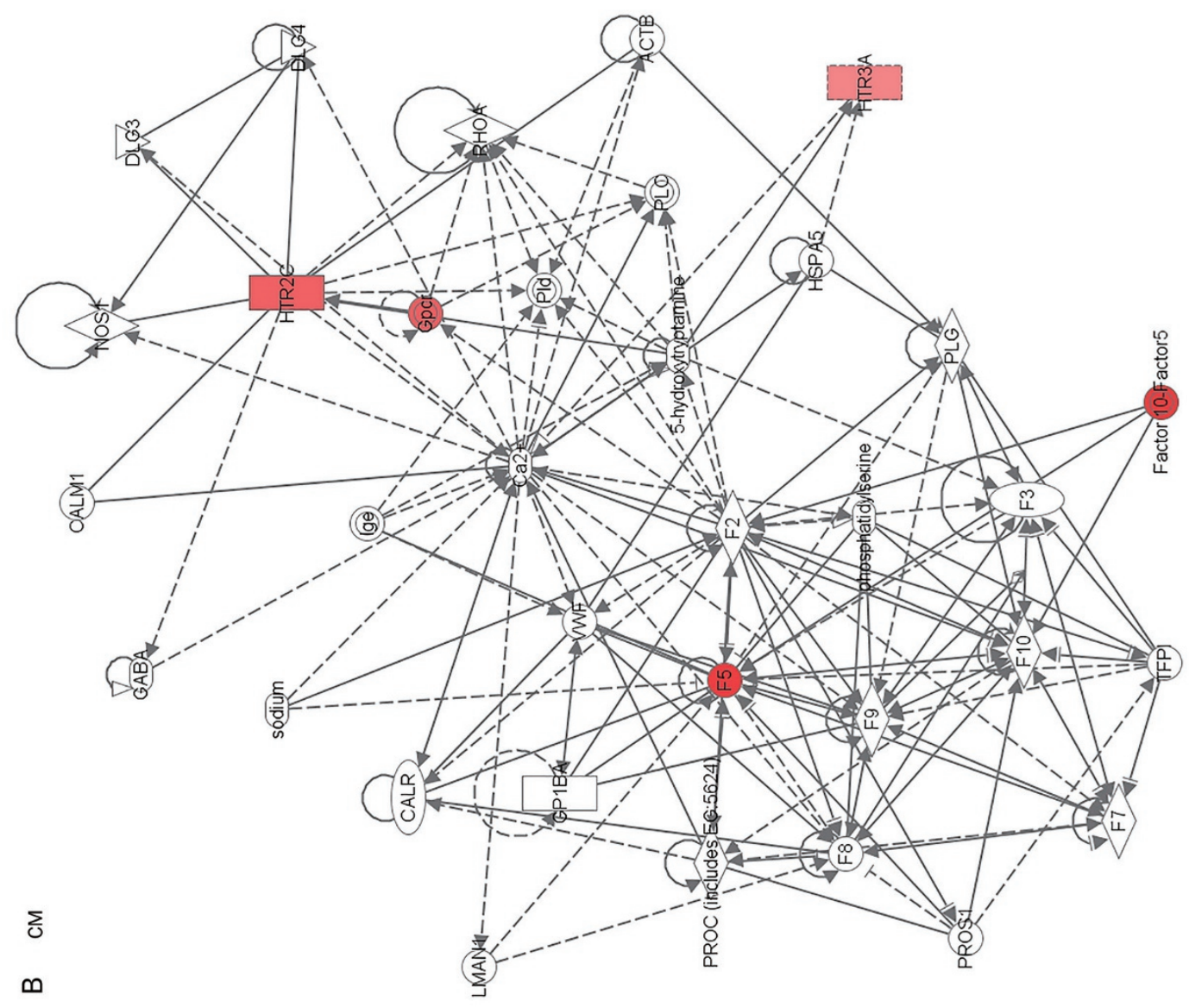

ఫ

क्षे

区

출

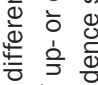

告

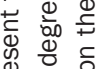

훙

过

응 홓

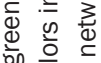

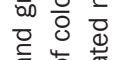

वे

ㄹ. ․ㅗㄹ

巴巛.

茫造

○

范跑。

可

茯高空

ब्र

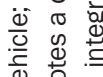

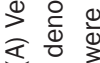

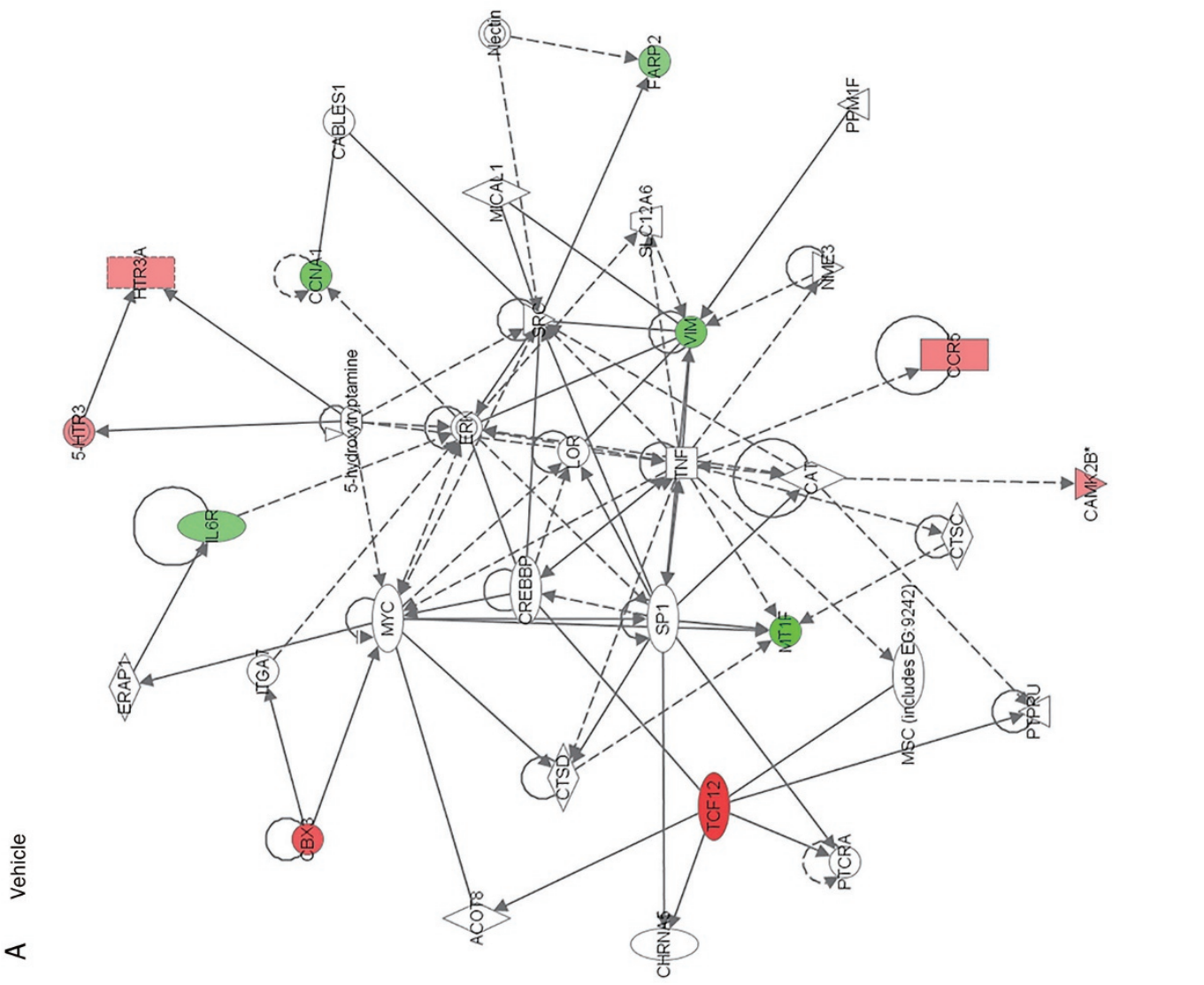

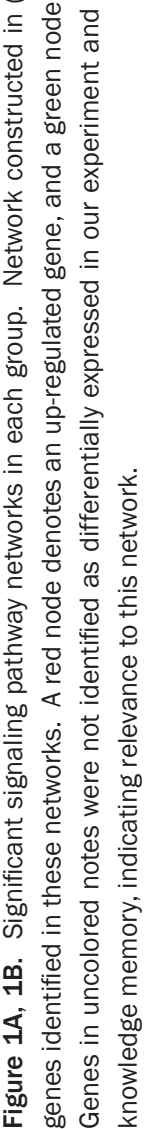




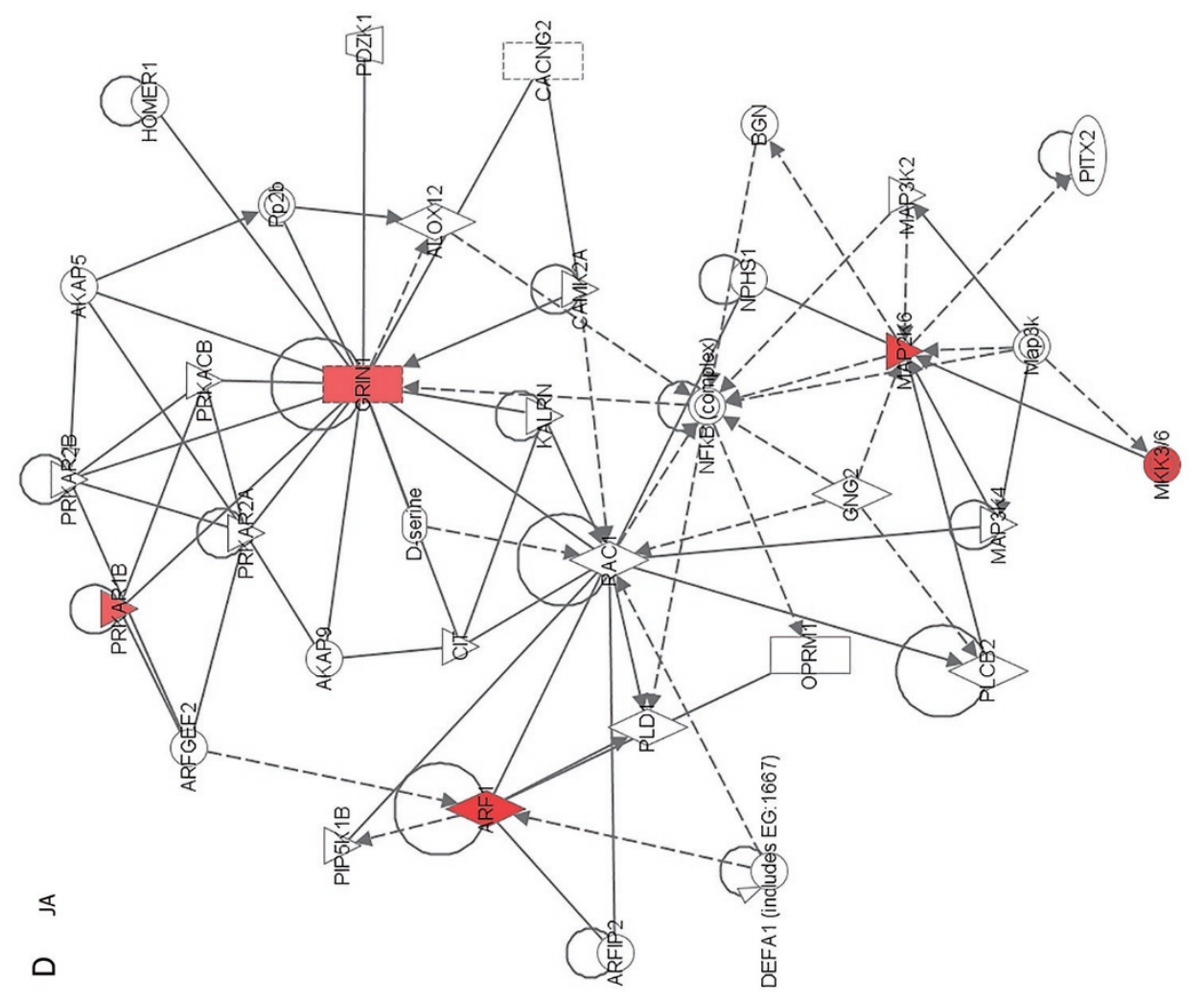

卷

过

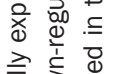

충

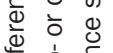

舫

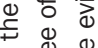

$\leftarrow$ के

屯.

产 焉

造

읗

ब.

क人 응

다유

这逜离

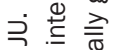

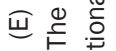

芒造

可

$\ddot{5}$ ㅇㅇㅇ

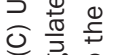

¿

鱼旁票

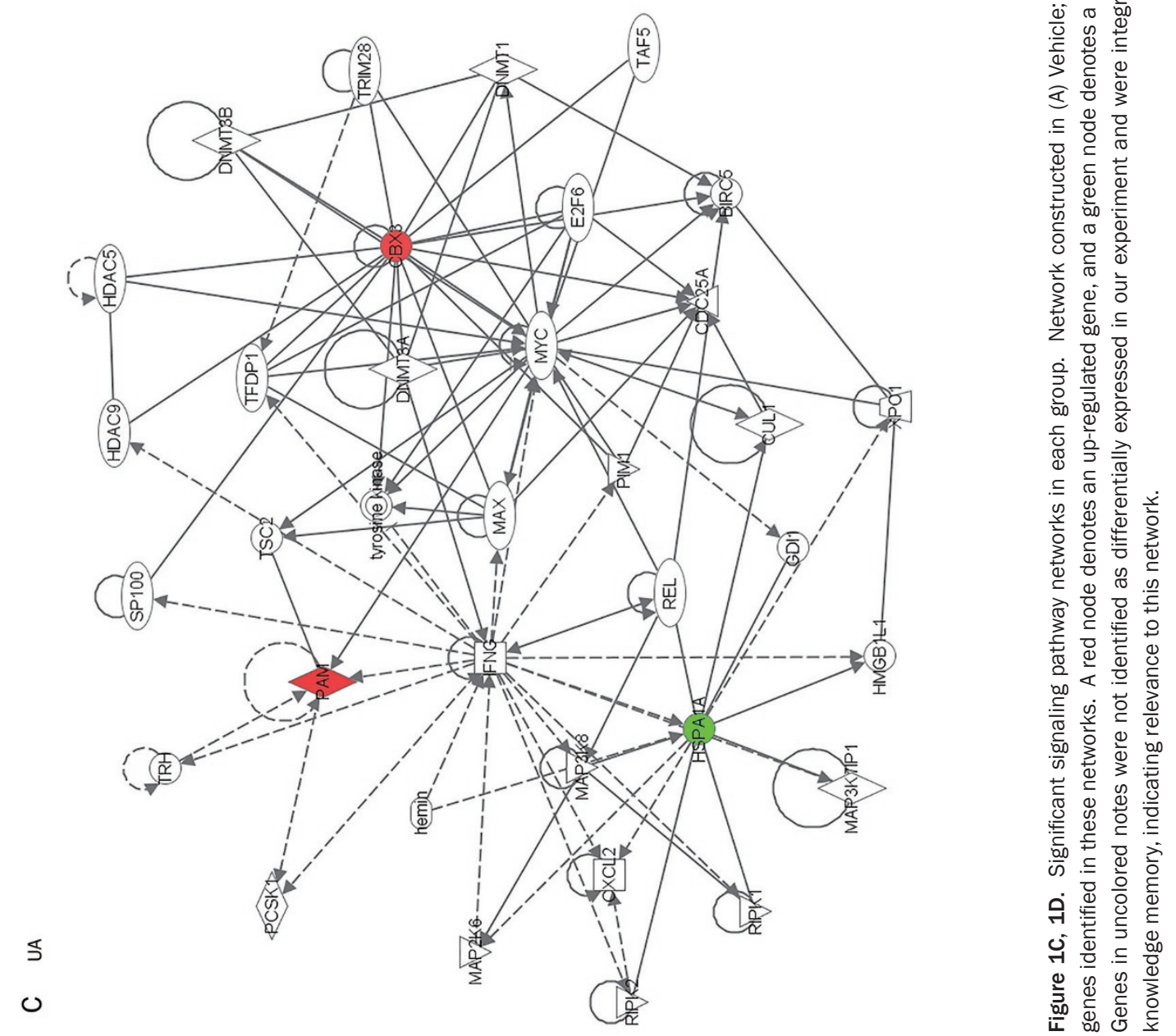




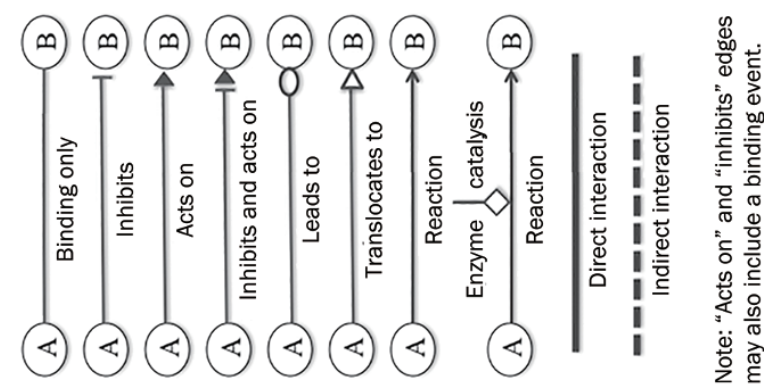
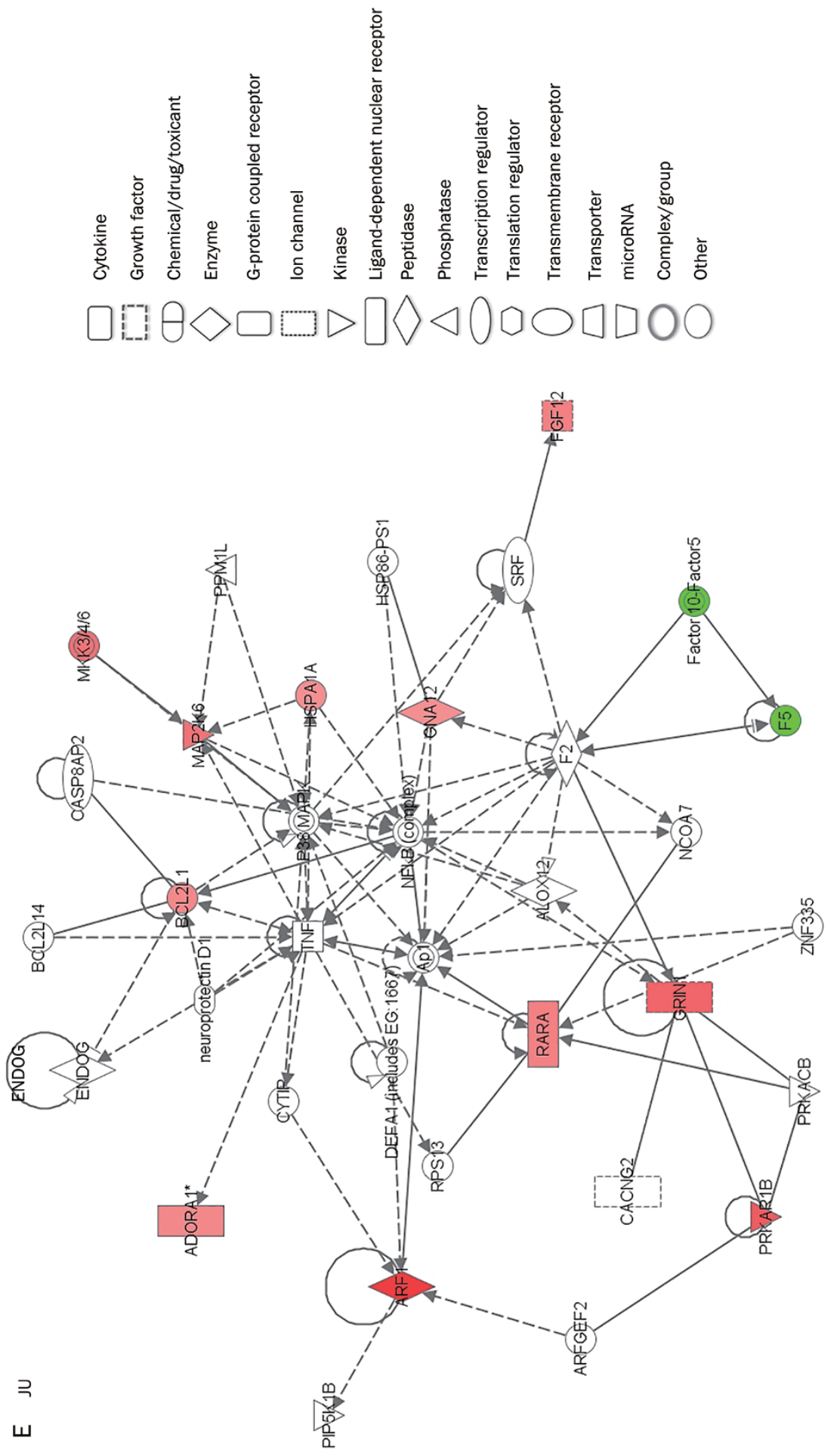

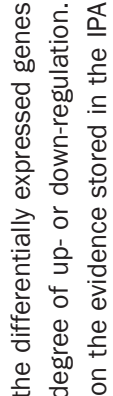

苛名总

舟

递

응

$\circ \frac{\infty}{2}$

등 웡

के

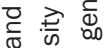

实密

う号 离

ए.

$\dddot{4}$

远密

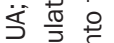

(⿹ 口)

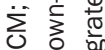

重完

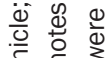

可

这

훵

竞市

항 흥

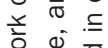

资

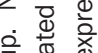

흥 한

등

$\stackrel{0}{\triangle}$

논

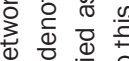

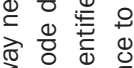

중 웡

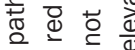

a) $\frac{0}{0}$

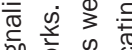

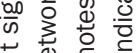

苋

는

के

ய

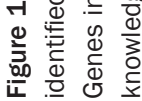


A

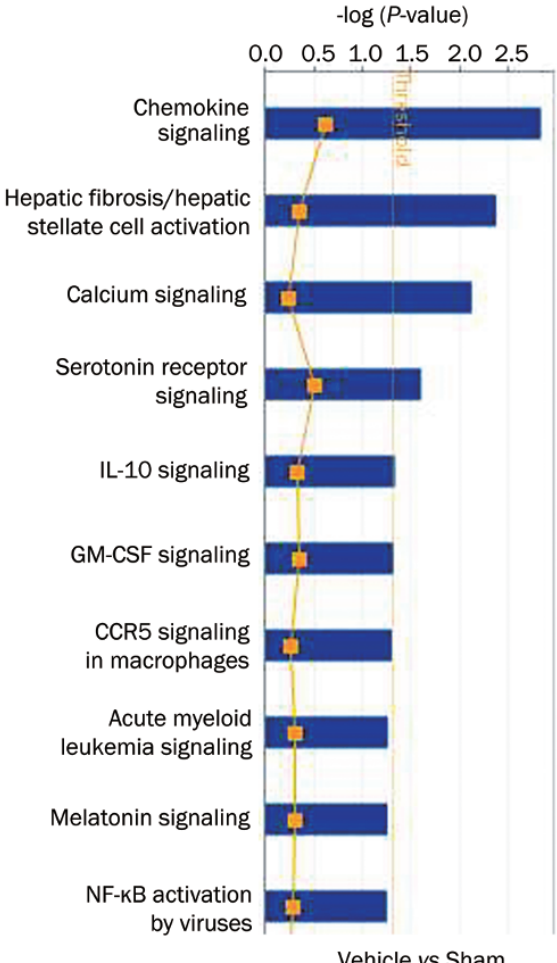

D

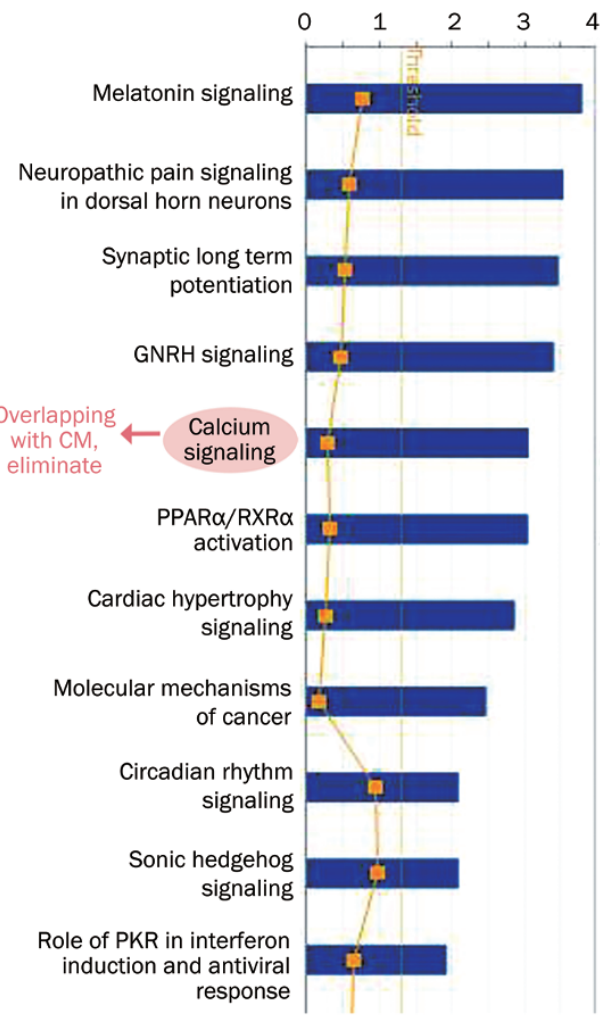

JA vs CM
B

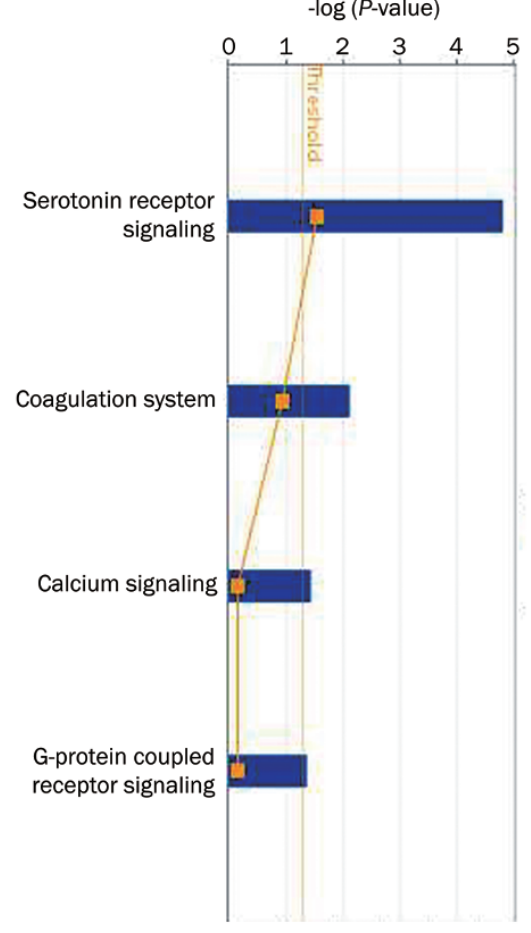

$\mathrm{CM}$ vs Vehicle

E

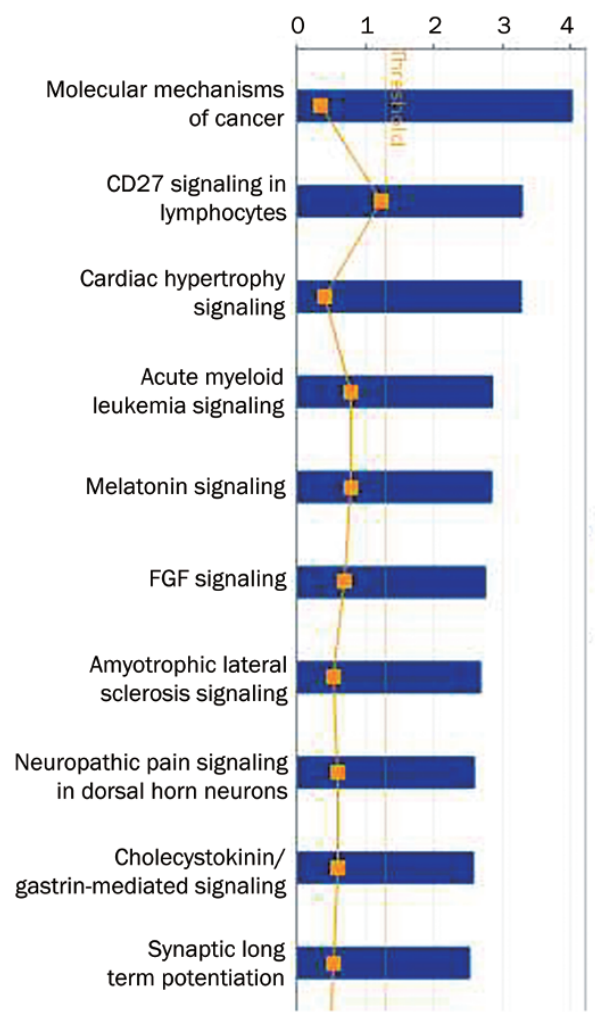

JU vs CM

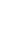

C

-log ( $P$-value $)$

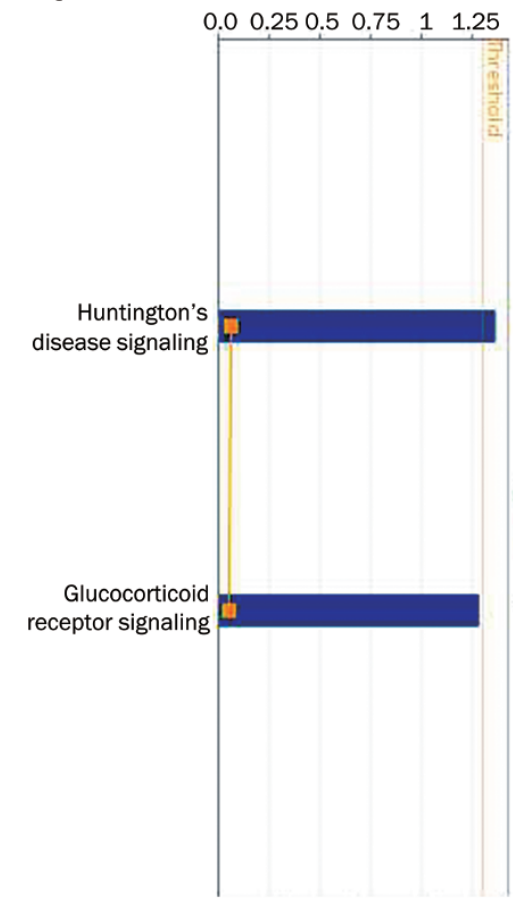

UA vs CM 
A

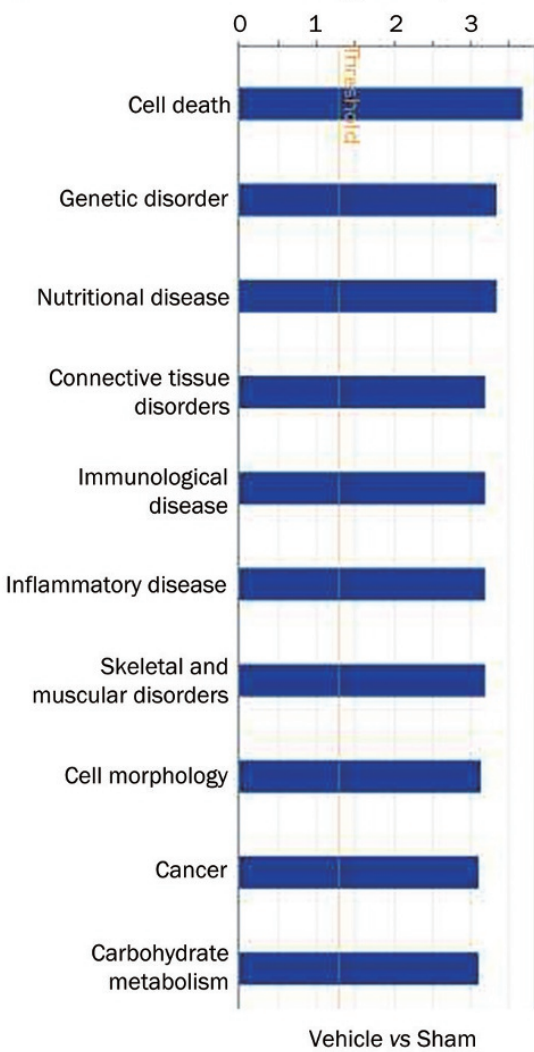

D

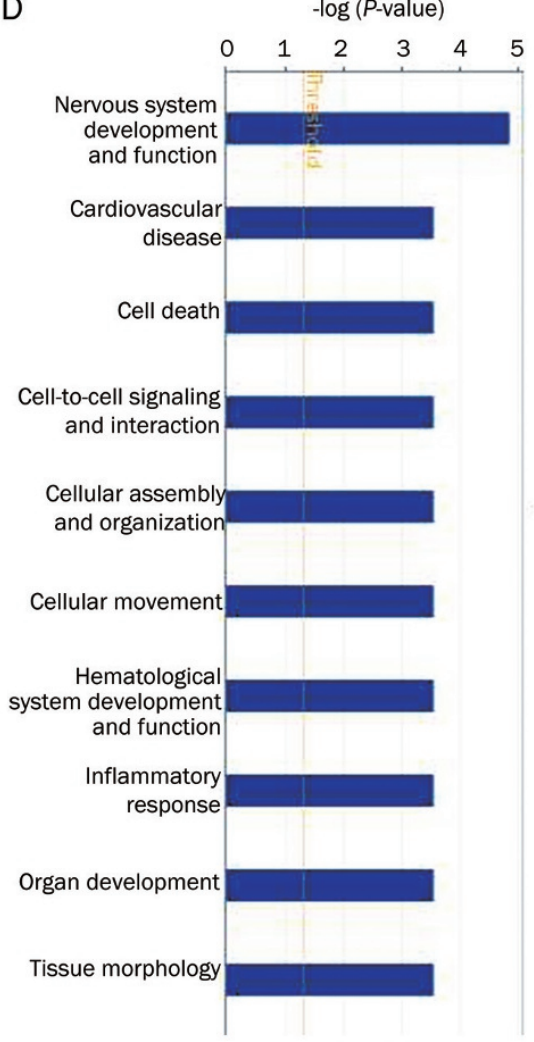

JA vs CM
B

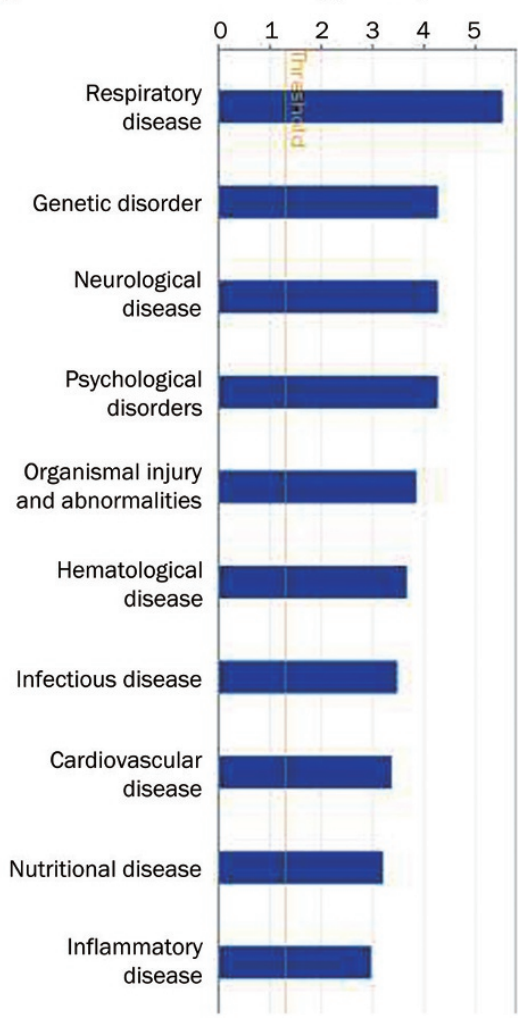

CM vs Vehicle

E

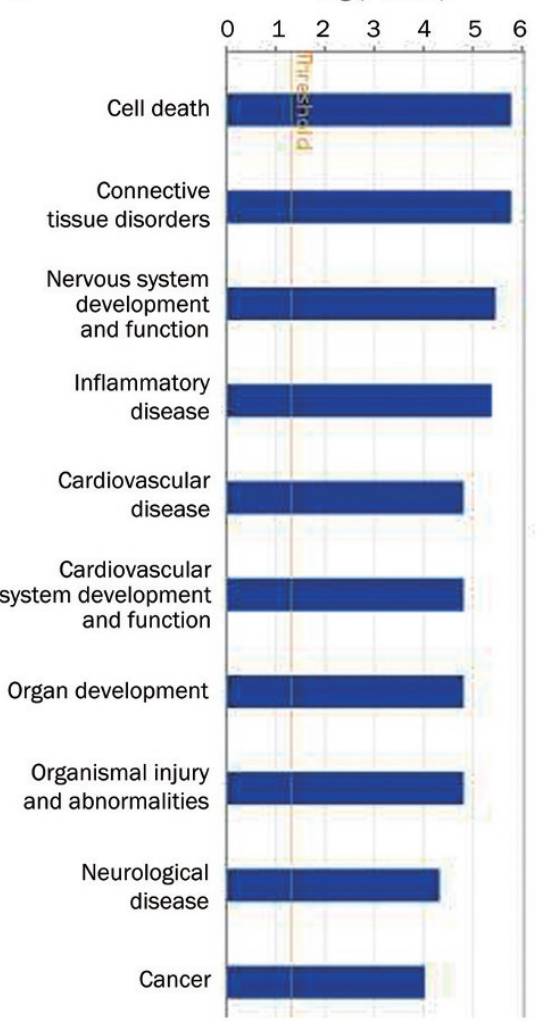

JU vs CM
C

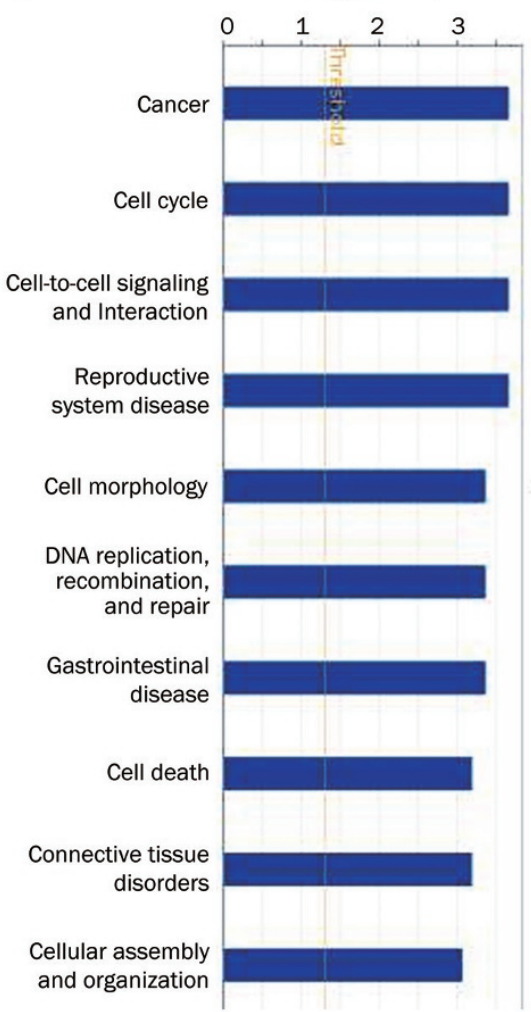

UA vs CM

Figure 3. Top 10 significant enriched biological functions in each group. Top 10 significant functions in (A) Vehicle group (vs Sham); (B) CM group (vs Vehicle); (C) UA group (vs CM); (D) JA group (vs CM); (E) JU group (vs CM). The yellow vertical line indicates a threshold of $P<0.05$. 
A

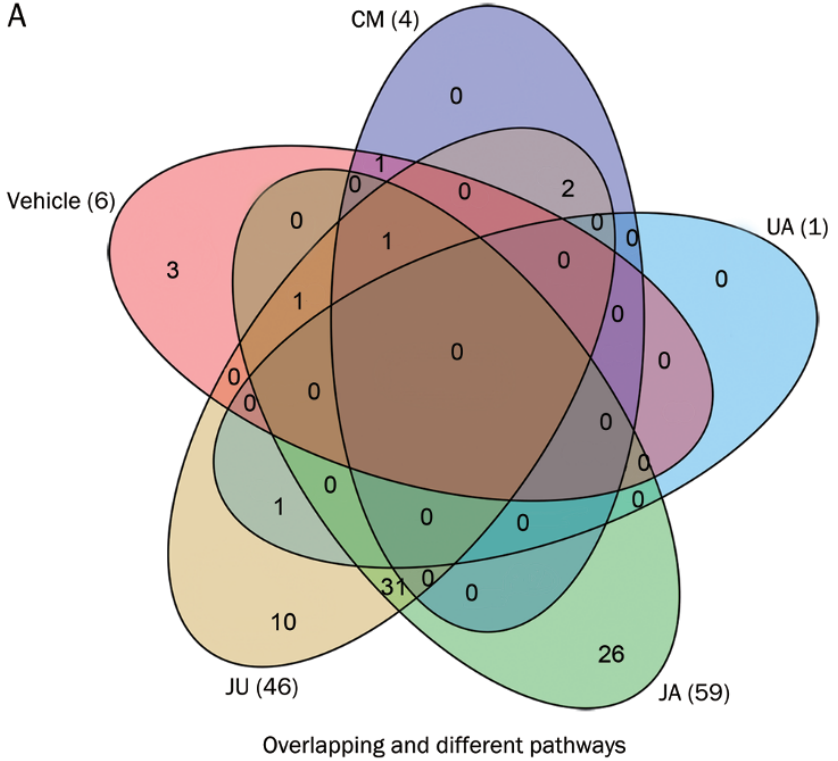

C

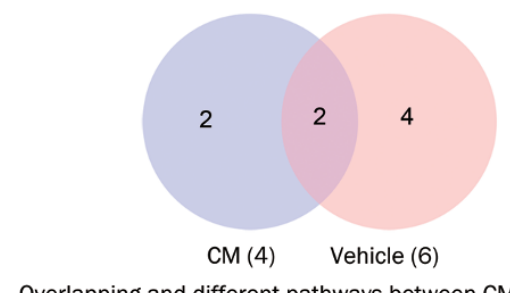

Overlapping and different pathways between $\mathrm{CM}$ and Vehicle

E

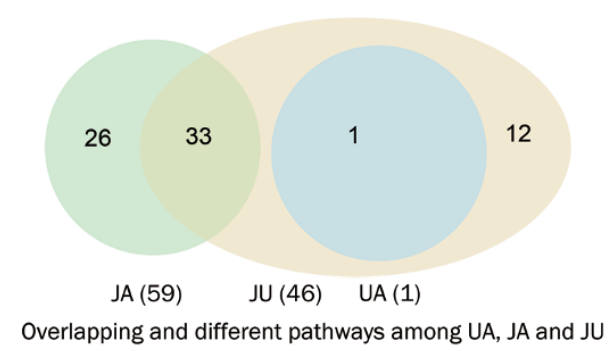

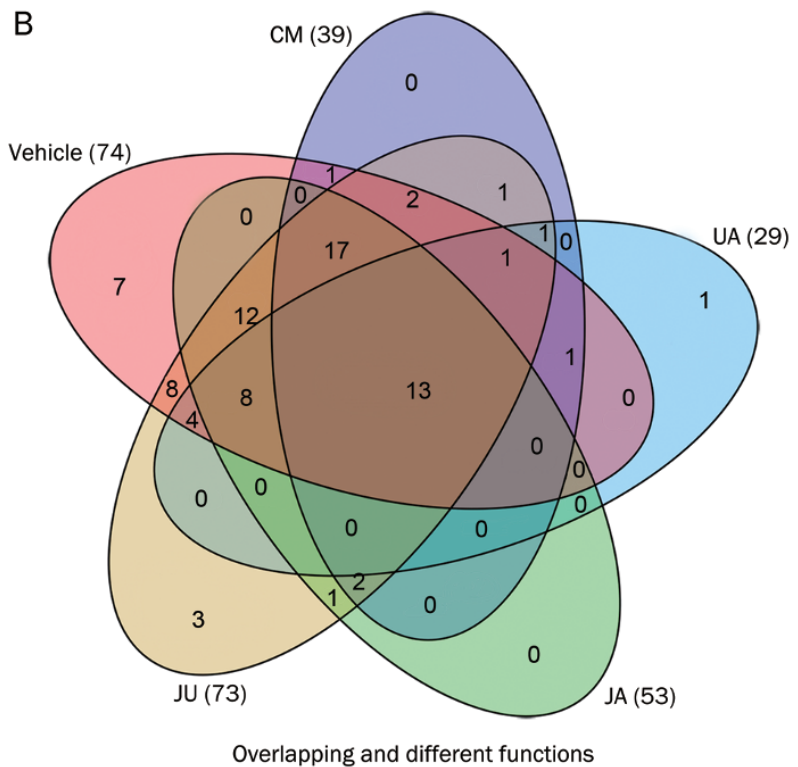

D

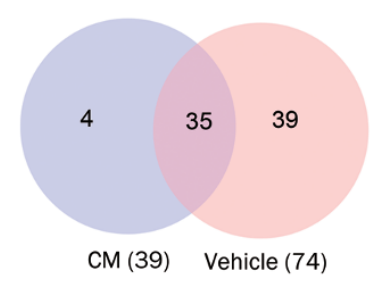

Overlapping and different functions between $\mathrm{CM}$ and Vehicle

$\mathrm{F}$

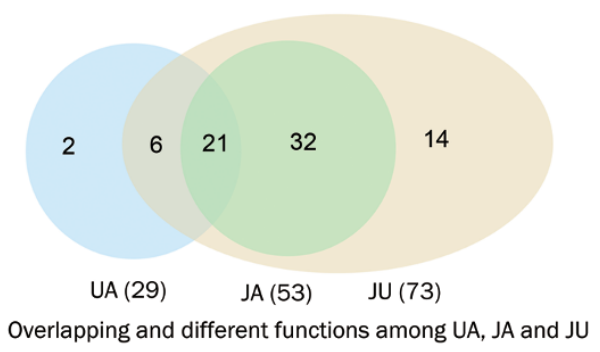

Figure 4. The Wayne figures of overlapping pathways and biological functions among groups. (A) Significant pathways overlapping among 5 different groups; (B) Significant enriched biological functions overlapping among 5 different groups; (C) Overlapping and different pathways between CM and Vehicle group; (D) Overlapping and different functions between CM and Vehicle group; (E) Overlapping and different pathways among UA, JA, and JU; (F) Overlapping and different functions among UA, JA, and JU. Red, purple, blue, green and yellow circles represent Vehicle, CM, UA, JA and JU group, respectively.

pathways (1, Huntington's Disease Signaling) and some of JA contributing pathways $(33,55.9 \%$ of the total) were integrated, and another 12 pathways emerged (Figure 4). To further derive the pure synergistic mechanism, we removed 2 pathways that overlapped with the CM or vehicle groups (Table 1 ). The remaining 10 core pathways and their actions are shown in Supplement table 2.

Notably, the JU group included the entirety of the JA (53) and majority of the UA $(27,93.1 \%$ of the 29 functions in the UA group) enriched functions. Interestingly, the overlapping functions in JU (overlapping with UA or JA, $80.8 \%$ of all functions in the JU group) cannot fully explain the functions found in the JU group. An additional 14 new functions were identi- fied. The classification of the emerging functions is shown in Figure 5. To further identify the core functions, 11 functions that overlapped with the CM or vehicle groups (Table 1) were excluded; this analysis left 3 new functions (humoral immune response, tissue development, visual system development and function), all of which belong to physiological system development and function category.

\section{Discussion}

When cells respond to stimuli, specifically to effective mixtures or multiple compounds, the molecular network is rewired. This is in contrast to the single target alterations that were previously suggested. Some rewiring, which may be 
A

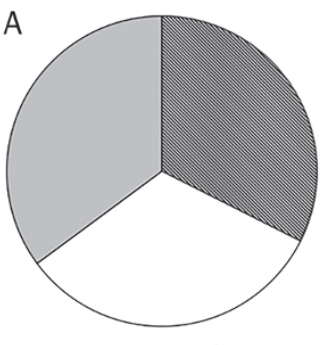

Vehicle (74)

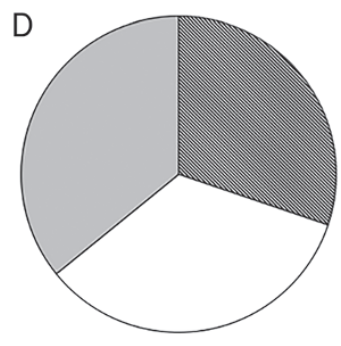

JA (53)

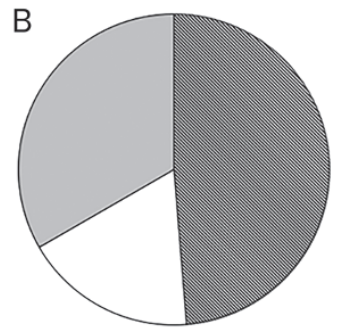

CM (39)

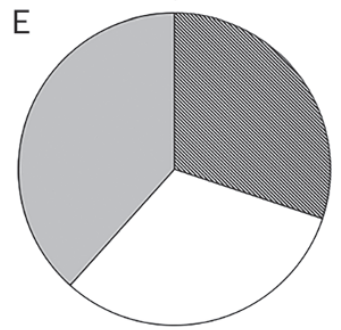

JU (73)

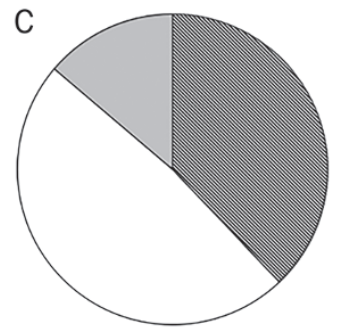

UA (29)

$\mathrm{F}$

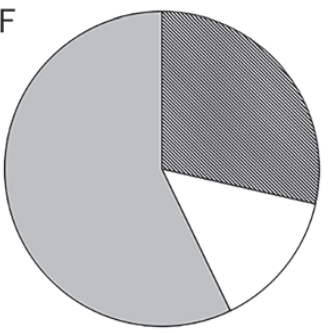

Distribution of 14 new emerging functions in JU group

Figure 5. Pie charts of distributions of the functions in each group and new emerging functions. Distributions of functions in (A) Vehicle group; (B) CM group; (C) UA group; (D) JA group; (E) JU group. (F) Distribution of 14 new emerging functions in JU group.

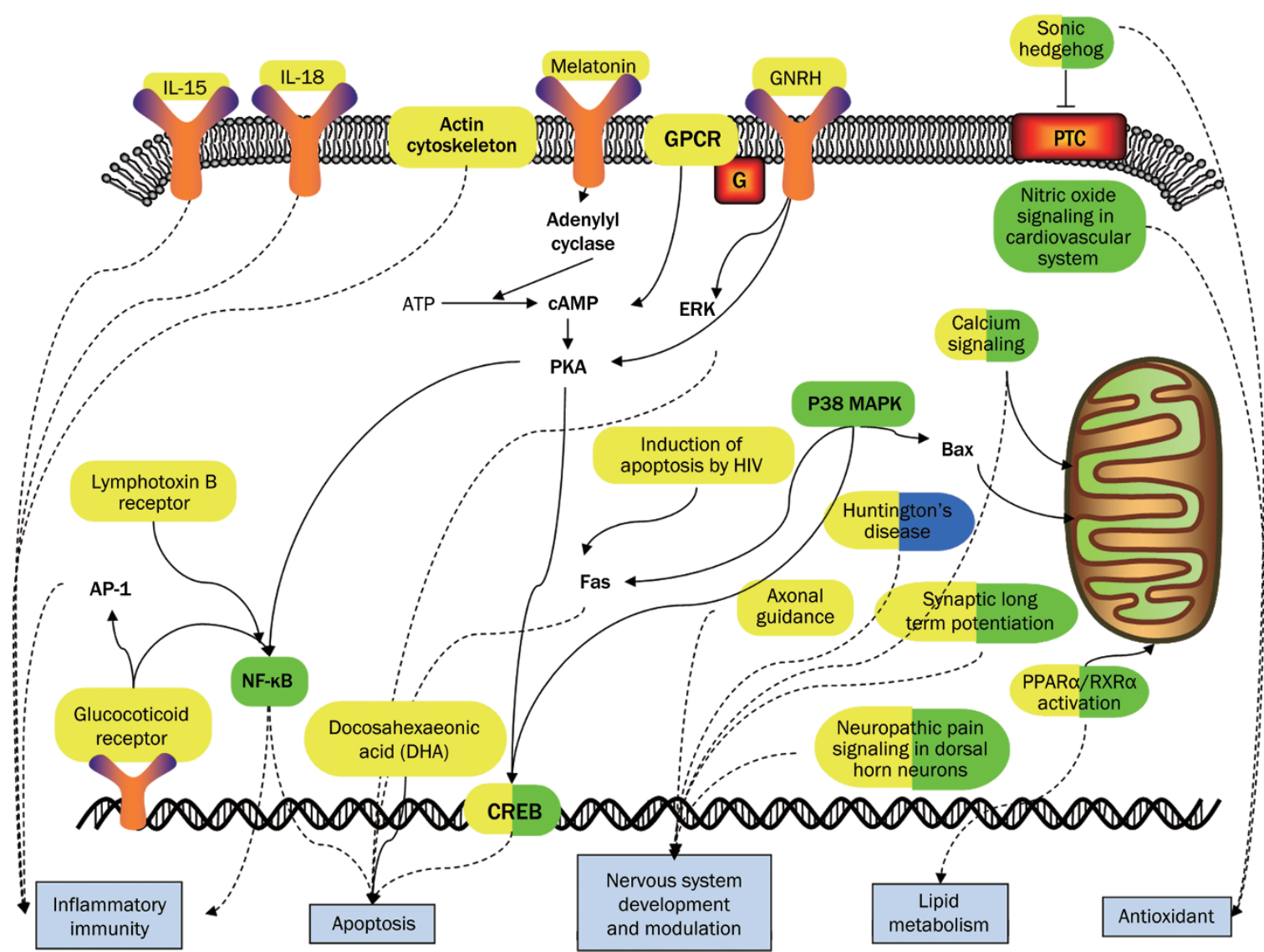

Figure 6. The proposed mechanisms of UA, JA, and JU. Pathways which are triggered by UA, JA, and JU are labeled with blue, green and yellow, respectively. The solid line represents the association between pathways; the dotted line represents the action of pathways. 
present in normal cells, casual cells, or cells under perturbation, is thought to be common, but not specific, for cerebral ischemia recovery. Rewiring that is specific to cerebral ischemia was termed a core mechanism. A core mechanism may contain key synergistic pharmacological mechanisms, particularly when two effective compounds are combined together. This is called pure synergism. A core mechanism cannot be detected by comparing positive phenotype compounds with the vehicle. In the current study, we attempted to eliminate the pathways that were observed in both negative and positive phenotype compounds; the remaining pathways were more specific for phenotype variation.

\section{Non-specific mechanism for phenotype variation in negative phenotype compounds}

Our previous results indicated that UA and JA could function synergistically in the ischemic hippocampus by regulating multiple targets and numerous cerebral ischemia-related pathways $^{[21-26]}$. To investigate whether the negative phenotype compounds play a role in modulating responses to perturbations or network rewiring, we analyzed the alteration in enriched pathways and functions in the negative phenotype compound (CM) group to demonstrate a non-specific pharmacological mechanism for phenotype variation.

In constructing the network according to the pattern of differentially expressed genes in the CM group, HTR2c and HTR3A were indicated as being relevant to the pathogenesis of neurological and psychiatric disorders, such as post-stroke depression $^{[27-30]}$. Interestingly, 4 canonical pathways enriched in $\mathrm{CM}$ were shown to be associated with neuroregulation or cerebral ischemia ${ }^{[26-31]}$. To elucidate the ineffectiveness of $\mathrm{CM}$ on phenotype, we conducted an additional analysis and found both Serotonin Receptor Signaling and Calcium Signaling in the vehicle group. This finding may indicate that although CM could modulate neuro-related pathways, pathological processes could not be reversed and the robustness of the cell signaling network could not be rewired by $\mathrm{CM}$. To explain this finding, we hypothesize the following: (1) the 4 pathways may be common pathways instead of core pathways in the cerebral ischemia pathological process and may not be sufficiently critical, specific, or sensitive for reducing ischemia infarction volume; and (2) alternative signaling pathways that compensate for pathways inhibited by CM may be not completely blocked. Furthermore, of the 39 biological functions observed, 35 functions $(89.7 \%$ of the total) were common to the vehicle group. This result was consistent with pathway analysis. Thus, we concluded that the network conversion caused by CM could not change the inherent properties of cerebral ischemia in the pathological state. This result validated the theory proposed in our previous study, which stated that several pathways should be targeted to optimize therapeutic efficacy ${ }^{[25]}$.

\section{Core mechanism for phenotype variation in positive phenotype compound}

We eliminated the pathways from the UA and JA groups that overlapped with the CM group to determine the core pathways and functions of the underlying core mechanism. We chose the top 10 core pathways as examples to elucidate the pharmacological effect of the these groups.

The pathway identified uniquely in the UA group, Huntington's disease signaling, is a pathway involved in neuropathology ${ }^{[32]}$. Five of the top 10 core pathways in the JA group (50\% of the total, ie, Melatonin Signaling, Neuropathic Pain Signaling in Dorsal Horn Neurons, Synaptic Long Term Potentiating, GNRH Signaling, and Sonic Hedgehog Signaling) have been widely reported to be associated with neuronal homeostasis ${ }^{[33-42]}$. Little evidence links the remaining 5 identified pathways in the JA group (PPARa/RXRa Activation, Cardiac Hypertrophy Signaling, Molecular Mechanisms of Cancer, Circadian Rhythm Signaling, and the Role of PKR in Interferon Induction and Antiviral Response) with cerebral ischemia processes. For example, few studies have suggested a relationship between cerebral ischemia and PPARa/RXRa Activation, as the function of this pathway involves lipid degradation and obesity ${ }^{[43]}$. In the JU group, 6 of the top 10 core pathways (Acute Myeloid Leukemia Signaling, Melatonin Signaling, FGF Signaling, Amyotrophic Lateral Sclerosis Signaling, Neuropathic Pain Signaling in Dorsal Horn Neurons, and Synaptic Long Term Potentiation) are widely accepted as involved in neuronal systems ${ }^{[44-49]}$. The other 4 of the top 10 core pathways (Molecular Mechanisms of Cancer, CD27 Signaling in Lymphocytes, Cardiac Hypertrophy Signaling, and Cholecystokinin Gastrin-mediated Signaling) showed no clear evidence of their association with cerebral ischemia ${ }^{[50,51]}$. We hypothesize that in response to perturbation, cells act as a whole. This leads to the activation of a series of pathways, which may not be limited to those involved in neuropathology. They may also include functions such as metabolic regulation. In addition to these top canonical pathways, many cerebral ischemia-related pathways were identified as core pathways in the positive phenotype groups. For example, P38 MAPK signaling was identified in the JA group, and the nuclear factor- $\mathrm{KB}(\mathrm{NF}-\mathrm{kB})$ signaling in the JU group is considered a classical inflammatory pathway ${ }^{[52]}$. The pathways involved may account for the pharmacological phenotype differences between the positive phenotype groups and the $\mathrm{CM}$ group. The core mechanisms of positive phenotype groups may primarily be neuronal homeostasis and neuropathology.

\section{Pure synergistic mechanism of pathways and networks con- vergence}

To further illuminate the pure synergistic mechanisms, we analyzed JU contributing pathways and found that the pathways may converge, rather than simply stack together in the combination group. The pathways identified in the JU group include specific targets of each single compound. For example, Huntington's disease signaling was identified in the UA and JU groups. Similarly, calcium signaling, PPARa/RXRa activation, IL-10 signaling, and others that were identified in the JA group were also identified in the JU group. This pattern may explain the additive effect of the two compounds. Additionally, it is worth noting that not all of the pathways involved 
in the JA group were identified in the JU group. For instance, IL-17 signaling, nitric oxide signaling in the cardiovascular system, and IL-6 signaling were observed in the JA group but not in the JU group. This finding led us to speculate that the therapeutic effect of a combination group could include at least a partial effect of the single compounds, rather than simple sum of the pharmacological effects. Moreover, JU may act on more than 10 pathways, which may contribute to the pure synergistic mechanism (Supplement Table 2). Some of these new pathways were involved in inflammatory immunity (IL-18 Signaling, Actin Cytoskeleton Signaling, Glucocorticoid Receptor Signaling, Lymphotoxin B Receptor Signaling, and IL-15 Signaling $\left.{ }^{[53-68]}\right)$. Some pathways were related to apoptosis [Docosahexaenoic Acid (DHA) Signaling, Role of Oct4 in Mammalian Embryo Stem Cell Pluripotency, Induction of Apoptosis by HIV, Small Cell Lung Cancer Signaling]. A final pathway, Axonal Guidance Signaling, is associated with nervous system development ${ }^{[69-77]}$. Therefore, we propose that the pure synergistic mechanism is focused on inflammation, immune responses, apoptosis, and nervous system development (Figure 6). These results validate the theory proposed in our previous study, which stated that the synergistic effects of drug combinations were generated by transmitting drug information, triggering different space-time effects through drug interactions, and generating new phenotypic correlation information sets ${ }^{[23]}$.

Additionally, the detail of overlapping function may provide a possible key to function alteration. The functions of the JU group included all of the functions of the JA group and a majority of the functions of the UA group (Figure 4). Notably, more than half $(8,57.1 \%)$ of these 14 functions that emerged in the JU group focus on physiological system development and function (Figure 5). Furthermore, 3 core functions (humoral immune response, tissue development, visual system development and function) belong to the physiological system development and function category. Therefore, we infer that modulations in physiological system development and function may be responsible for the increased efficacy of the combined therapy compared with each of the single compounds. Interestingly, these 3 core functions are, to some extent, consistent with the functions regulated by the 10 core pathways referred to in our previous analysis. These results also validate the idea that, when combined, UA and JA integrate and generate more efficacy than a simple additive action, which would suggest and produce additional targeting pathways and biological functions; these additional targets are primarily involved in inflammation, immune responses, apoptosis, and nervous system development.

In the current study, to reveal a pure synergistic mechanism, we integrated phenotype screening and high-throughput genomic analysis to enrich pathways and construct networks. Several features of this approach may contribute substantially to the discovery and analysis of synergism: (1) phenotype screening, a reverse pharmacological method, provides promising access to efficacy for further mechanism exploration; and (2) pure synergism, excluding the impact of ineffective com- pounds and non-specific pathways for outcomes, identifies core pathways for phenotype variations. As an initial effort for pure synergism, this approach was a qualitative analysis of pathway alterations and network rewiring. Further studies will be devoted to the quantitative analysis of core pathways for further validation.

\section{Conclusion}

The pure synergism between UA and JA, which underlie 10 new core pathways and 3 new core functions, is involved in inflammation, immune responses, apoptosis, and nervous system development.

\section{Abbreviation}

$\mathrm{CM}$, Concha margaritifera; UA, Ursodeoxycholic acid; JA, Jasminoidin; JU, Jasminoidin combined with Ursodeoxycholic acid; STKE, Science signal transduction knowledge environment; ANOVA, Analysis of variance; GnRH, Gonadotropinreleasing hormone; GPCR, G-protein coupled receptor; NF-kB, Nuclear factor-кB; MAPK, Mitogen activated protein kinases; PPARa/RXRa, Peroxisome proliferators-activated receptor a/ retinoid $\mathrm{X}$ receptor $\mathrm{a}$; FGF, Fibroblast growth factor; IL, Interleukin.

\section{Acknowledgements}

This study was supported by Hi-Tech Research and Development Program of China (863) and National 11th Five-years plan Supporting R\&D Project (2006BAI08B04-06).

\section{Author contribution}

Zhong WANG directed the research and revised the manuscript; Peng-qian WANG performed the research and wrote the paper; Bing LI, Jun LIU and Ying-ying ZHANG modified tables and revised the manuscipt; Ya-nan YU, Xiao-xu ZHANG, Ye YUAN, Zhi-li GUO and Hong-li WU analyzed the experimental data, Hai-xia LI, Hai-xia DANG and Shanshan GUO revised the manuscript.

\section{Supplementary information}

Supplementary information is available at Acta Pharmacologica Sinica's website.

\section{References}

1 Wang F, Liang W, Lei C, Kinden R, Sang H, Xie Y, et al. Combination of $\mathrm{HBO}$ and memantine in focal cerebral ischemia: is there a synergistic effect? Mol Neurobiol 2014. Doi:.

2 Wang Z, Liu J, Cheng Y, Wang Y. Fangjiomics: in search of effective and safe combination therapies. J Clin Pharmacol 2011; 51: 113251.

3 Jia J, Zhu F, Ma X, Cao ZW, Li YX, Chen YZ. Mechanisms of drug combinations: interaction and network perspectives. Nat Rev Drug Discov 2009; 8: 111-28.

4 Vitali F, Mulas F, Marini P, Bellazzi R. Network-based target ranking for polypharmacological therapies. J Biomed Inform 2013; 46: 876-81.

5 Jin G, Zhao H, Zhou X, Wong ST. An enhanced Petri-net model to predict synergistic effects of pairwise drug combinations from gene microarray data. Bioinformatics 2011; 27: i310-6. 
6 Tang J, Karhinen L, Xu T, Szwajda A, Yadav B, Wennerberg K, et al. Target inhibition networks: predicting selective combinations of druggable targets to block cancer survival pathways. PLoS Comput Biol 2013; 9: e1003226.

7 Goldoni M, Tagliaferri S. Dose-response or dose-effect curves in in vitro experiments and their use to study combined effects of neurotoxicants. Methods Mol Biol 2011; 758: 415-34.

8 Loewe S. The problem of synergism and antagonism of combined drugs. Arzneimittelforschung 1953; 3: 285-90.

9 Novick SJ. A simple test for synergy for small number of combinations. Stat Med 2013; 13: 5145-55.

10 Bliss $\mathrm{C}$. The toxicity of poisons applied jointly. Annals of applied biology 1939; 26: 585-615.

11 Yan $\mathrm{H}$, Zhang B, Li S, Zhao Q. A formal model for analyzing drug combination effects and its application in TNF- $\alpha$-induced NF-KB pathway. BMC Syst Biol 2010; 4: 50.

12 Chou T-C, Talalay P. Analysis of combined drug effects: a new look at a very old problem. Trends Pharmacol Sci 1983; 4: 450-4.

13 Peterson JJ, Novick SJ. Nonlinear blending: a useful general concept for the assessment of combination drug synergy. J Recept Signal Transduct Res 2007; 27: 125-46.

14 Zhang Y, Smolen P, Baxter DA, Byrne JH. Computational analyses of synergism in small molecular network motifs. PLoS Comput Biol 2014; 10: e1003524.

15 Wang Z, Wang YY. Modular pharmacology: deciphering the interacting structural organization of the targeted networks. Drug Discov Today 2013; 18: 560-6.

16 Wang Z, Wang Y. Navigating personalized medicine dependent on modular flexibility. Trends Mol Med 2013; 19: 393-5.

17 Ghosh S, Basu A. Network medicine in drug design: implications for neuroinflammation. Drug Discov Today 2012; 17: 600-7.

18 Jiang WL, Xu Y, Zhang SP, Zhu HB, Hou J. Tricin 7-glucoside protects against experimental cerebral ischemia by reduction of NF-KB and HMGB1 expression. Eur J Pharm Sci 2012; 45: 50-7.

19 Patwardhan B, Vaidya AD, Chorghade M, Joshi SP. Reverse pharmacology and systems approaches for drug discovery and development. Curr Bioact Compd 2008; 4: 201-12.

20 Willcox ML, Graz B, Falquet J, Diakite C, Giani S, Diallo D. A “reverse pharmacology" approach for developing an anti-malarial phytomedicine. Malar J 2011; 10: S8.

21 Chen Y, Zhou C, Yu Y, Liu J, Jing Z, Lv A, et al. Variations in target gene expression and pathway profiles in the mouse hippocampus following treatment with different effective compounds for ischemia-reperfusion injury. Naunyn Schmiedeberg Arch Pharmacol 2012; 385: 797-806.

22 Chen Y, Meng F, Fang H, Yu Y, Liu J, Jing Z, et al. Hierarchical profiles of signaling pathways and networks reveal two complementary pharmacological mechanisms. CNS Neurol Disord Drug Targets 2013; 12 : 882-93.

23 Liu J, Zhou CX, Zhang ZJ, Wang LY, Jing ZW, Wang Z. Synergistic mechanism of gene expression and pathways between jasminoidin and ursodeoxycholic acid in treating focal cerebral Ischemia-reperfusion injury. CNS Neurosci Ther 2012; 18: 674-82.

24 Zhang YY, Li HX, Chen YY, Fang H, Yu YN, Liu J, et al. Convergent and divergent pathways decoding hierarchical additive mechanisms in treating cerebral ischemia-reperfusion injury. CNS Neurosci Ther 2014; 20: 253-63.

25 Wang Z, Jing ZW, Zhou CX, Zhang L, Cheng J, Zhang ZJ, et al. Fusion of core pathways reveals a horizontal synergistic mechanism underlying combination therapy. Eur J Pharmacol 2011; 667: 278-86.

26 Liu J, Zhang ZJ, Zhou CX, Wang Y, Cheng YY, Darrel Duan DY, et al.
Outcome-dependent global similarity analysis of imbalanced core signaling pathways in ischemic mouse hippocampus. CNS Neurol Disord Drug Targets 2012; 11: 1070-82.

27 Tang W, Tang N, Liao C, Liang H, Mok V, Ungvari G, et al. Serotonin receptor $2 \mathrm{C}$ gene polymorphism associated with post-stroke depression in Chinese patients. Genet Mol Res 2013; 12: 1546.

28 Fillingim R, Wallace M, Herbstman D, Ribeiro-Dasilva M, Staud R. Genetic contributions to pain: a review of findings in humans. Oral Dis 2008; 14: 673-82.

29 Monyer $\mathrm{H}$, Inta $\mathrm{D}$, inventors; Serotonin $5-\mathrm{HT}_{3 \mathrm{~A}}$ receptors in treatment of neurological and psychiatric disorders. US patent $12 / 305,819$. 2007 June 21.

30 Xia L, Deloménie C, David I, Rainer Q, Marouard M, Delacroix H, et al. Ventral hippocampal molecular pathways and impaired neurogenesis associated with $5-\mathrm{HT}_{1 \mathrm{~A}}$ and $5-\mathrm{HT}_{1 \mathrm{~B}}$ receptors disruption in mice. Neurosci Lett 2012; 521: 20.

31 Jickling GC, Liu D, Stamova B, Ander BP, Zhan X, Lu A, et al. Hemorrhagic transformation after ischemic stroke in animals and humans. J Cereb Blood Flow Metab 2013; 34: 185-99.

32 Steffan J S, Kazantsev A, Spasic-Boskovic O, Greenwald M, Zhu Y-Z, Gohler H, et al. The Huntington's disease protein interacts with p53 and CREB-binding protein and represses transcription. Proc Natl Acad Sci U S A 2000, 97: 6763-8.

33 Abrajano JJ, Qureshi IA, Gokhan S, Zheng D, Bergman A, Mehler MF. REST and CoREST modulate neuronal subtype specification, maturation and maintenance. PloS One 2009; 4: e7936.

34 Dragicevic N, Delic V, Cao C, Copes N, Lin X, Mamcarz M, et al. Caffeine increases mitochondrial function and blocks melatonin signaling to mitochondria in Alzheimer's mice and cells. Neuropharmacology 2012; 63: 1368-79.

35 Chu C, Xu B, Huang W. GnRH analogue attenuated apoptosis of rat hippocampal neuron after ischemia-reperfusion injury. J Mol Histol 2010; 41: 387-93.

36 Woods NK, Padmanabhan J. Neuronal calcium signaling and Alzheimer's disease. Adv Exp Med Biol 2012; 740: 1193-217.

37 Demuro A, Parker I, Stutzmann GE. Calcium signaling and amyloid toxicity in Alzheimer disease. J Biol Chem 2010; 285: 12463-8.

38 Sun W, McConnell E, Pare JF, Xu Q, Chen M, Peng W, et al. Glutamatedependent neuroglial calcium signaling differs between young and adult brain. Science 2013; 339: 197-200.

39 Chakroborty S, Kim J, Schneider C, Jacobson C, Molgó J, Stutzmann GE. Early presynaptic and postsynaptic calcium signaling abnormalities mask underlying synaptic depression in presymptomatic Alzheimer's disease mice. J Neurosci 2012; 32: 8341-53.

40 Araújo GL, Araújo JA, Shroeder T, Tort A, Costa M. Sonic hedgehog signaling regulates mode of cell division of early cerebral cortex progenitors and increases. Front Cell Neurosci 2014; 8: 77.

41 Li T, Zhang J, Liu RY, Lian ZG, Chen XL, Ma L, et al. The role of the sonic hedgehog signaling pathway in early brain injury after experimental subarachnoid hemorrhage in rats. Neurosci Lett 2013; 552: 81-6.

42 Zhang L, Chopp M, Meier DH, Winter S, Wang L, Szalad A, et al. Sonic hedgehog signaling pathway mediates cerebrolysin-improved neurological function after stroke. Stroke 2013; 44: 1965-72.

43 Yoshikawa T, Ide T, Shimano H, Yahagi N, Amemiya-Kudo M, Matsuzaka $\mathrm{T}$, et al. Cross-talk between peroxisome proliferator-activated receptor (PPAR) $\alpha$ and liver $X$ receptor (LXR) in nutritional regulation of fatty acid metabolism. I. PPARs suppress sterol regulatory element binding protein-1c promoter through inhibition of LXR signaling. Mol Endocrinol 2003; 17: 1240-54.

44 Frakes AE, Ferraiuolo L, Haidet-Phillips AM, Schmelzer L, Braun L, 
Miranda $\mathrm{CJ}$, et al. Microglia induce motor neuron death via the classical NF-KB pathway in amyotrophic lateral sclerosis. Neuron 2014; 81: 1009-23.

45 Spradling KD, Lumley LA, Robison CL, Meyerhoff JL, Dillman JF. Transcriptional responses of the nerve agent-sensitive brain regions amygdala, hippocampus, piriform cortex, septum, and thalamus following exposure to the organophosphonate anticholinesterase sarin. J Neuroinflam 2011; 8: 2-21.

46 Cohen MA, Itsykson P, Reubinoff BE. The role of FGF-signaling in early neural specification of human embryonic stem cells. Dev Biol 2010; 340: 450-8.

47 Chen J, Lai F, Niswander L. The ubiquitin ligase $\mathrm{mLin} 41$ temporally promotes neural progenitor cell maintenance through FGF signaling. Genes Dev 2012; 26: 803-15.

48 Liu J, Wang Y, Akamatsu Y, Lee CC, Stetler RA, Lawton MT, et al. Vascular remodeling after ischemic stroke: Mechanisms and therapeutic potentials. Prog Neurobiol 2014; 115: 138-56.

49 Murakami M, Sakurai T. Role of fibroblast growth factor signaling in vascular formation and maintenance: orchestrating signaling networks as an integrated system. Wiley Interdiscip Rev Syst Biol Med 2012; 4: 615-29.

50 Huang ZM, Gao E, Fonseca FV, Hayashi H, Shang X, Hoffman NE, et al. Convergence of $\mathrm{G}$ protein-coupled receptor and S-nitrosylation signaling determines the outcome to cardiac ischemic injury. Sci Signal 2013; 6: ra95.

51 Sun J, Nguyen T, Kohr MJ, Menazza S, Murphy E. Cardioprotective role of caveolae in ischemia-reperfusion injury. Transl Med 2013; 3: 114.

52 Qin WY, Luo Y, Chen L, Tao T, Li Y, Cai YL, et al. Electroacupuncture could regulate the NF-KB signaling pathway to ameliorate the inflammatory injury in focal cerebral ischemia/reperfusion model rats. Evid Based Complement Alternat Med 2013; 2013: 924541.

53 Akira S. The role of IL-18 in innate immunity. Curr Opin Immunol 2000; 12: 59-63.

54 Fann DY, Lee SY, Manzanero S, Chunduri P, Sobey CG, Arumugam TV. Pathogenesis of acute stroke and the role of inflammasomes. Ageing Res Rev 2013; 12: 941-66.

55 Mallat Z, Corbaz A, Scoazec A, Graber P, Alouani S, Esposito B, et al. Interleukin-18/interleukin-18 binding protein signaling modulates atherosclerotic lesion development and stability. Circ Res 2001; 89: e41-5.

56 Blankenberg S, Tiret L, Bickel C, Peetz D, Cambien F, Meyer J, et al. Interleukin-18 is a strong predictor of cardiovascular death in stable and unstable angina. Circulation 2002; 106: 24-30.

57 Dustin ML, Cooper JA. The immunological synapse and the actin cytoskeleton: molecular hardware for T cell signaling. Nat Immunol 2000; 1: 23-9.

58 Gisselsson LL, Matus A, Wieloch T. Actin redistribution underlies the sparing effect of mild hypothermia on dendritic spine morphology after in vitro ischemia. J Cereb Blood Flow Metab 2005; 25: 1346-55.

59 Schmidt A, Hall MN. Signaling to the actin cytoskeleton. Annu Rev Cell Dev Biol 1998; 14: 305-38.

60 May RC, Machesky LM. Phagocytosis and the actin cytoskeleton. J Cell Sci 2001; 114: 1061-77.

61 Smoak KA, Cidlowski JA. Mechanisms of glucocorticoid receptor signaling during inflammation. Mech Ageing Dev 2004; 125: 697-706.

62 Zhang Z, Jones S, Hagood JS, Fuentes NL, Fuller GM. STAT3 acts as a co-activator of glucocorticoid receptor signaling. J Biol Chem 1997; 272: 30607-10.

63 VanArsdale TL, VanArsdale SL, Force WR, Walter BN, Mosialos G, Kieff E, et al. Lymphotoxin- $\beta$ receptor signaling complex: role of tumor necrosis factor receptor-associated factor 3 recruitment in cell death and activation of nuclear factor kB. Proc Natl Acad Sci U S A 1997; 94: 2460-5.

64 Wang Y, Koroleva EP, Kruglov AA, Kuprash DV, Nedospasov SA, Fu YX, et al. Lymphotoxin beta receptor signaling in intestinal epithelial cells orchestrates innate immune responses against mucosal bacterial infection. Immunity 2010; 32: 403-13.

65 Onder L, Danuser R, Scandella E, Firner S, Chai Q, Hehlgans T, et al. Endothelial cell-specific lymphotoxin- $\beta$ receptor signaling is critical for lymph node and high endothelial venule formation. J Exp Med 2013; 210: 465-73.

66 DePaolo R, Abadie V, Tang F, FehIner-Peach H, Hall J, Wang W, et al. Co-adjuvant effects of retinoic acid and IL-15 induce inflammatory immunity to dietary antigens. Nature 2011; 471: 220-4.

67 Gorina R, Font-Nieves M, Márquez-Kisinousky L, Santalucia T, Planas AM. Astrocyte TLR4 activation induces a proinflammatory environment through the interplay between MyD88-dependent NFKB signaling, MAPK, and Jak1Stat1 pathways. Glia 2011; 59: 242-55.

68 Waldmann TA. The biology of IL-15: implications for cancer therapy and the treatment of autoimmune disorders. J Investig Dermatol Symp Proc 2013; 16: S28-30.

69 Salem Jr N, Litman B, Kim HY, Gawrisch K. Mechanisms of action of docosahexaenoic acid in the nervous system. Lipids 2001; 36 : 945-59.

70 Chang CY, Kuan YH, Li JR, Chen WY, Ou YC, Pan HC, et al. Docosahexaenoic acid reduces cellular inflammatory response following permanent focal cerebral ischemia in rats. J Nutr Biochem 2013; 24 : 2127-37.

71 Eady TN, Belayev L, Khoutorova L, Atkins KD, Zhang C, Bazan NG. Docosahexaenoic acid signaling modulates cell survival in experimental ischemic stroke penumbra and initiates long-term repair in young and aged rats. PloS One 2012; 7: e46151.

72 Loh YH, Wu Q, Chew JL, Vega VB, Zhang W, Chen X, et al. The Oct4 and Nanog transcription network regulates pluripotency in mouse embryonic stem cells. Nat Genet 2006; 38: 431-40.

73 Février M, Dorgham K, Rebollo A. CD4+ T cell depletion in human immunodeficiency virus (HIV) infection: role of apoptosis. Viruses 2011; 3: 586-612.

74 Bruce-Keller AJ, Turchan-Cholewo J, Smart EJ, Geurin T, Chauhan A, Reid $\mathrm{R}$, et al. Morphine causes rapid increases in glial activation and neuronal injury in the striatum of inducible HIV-1 tat transgenic mice. Glia 2008; 56: 1414-27.

75 Bashaw GJ, Klein R. Signaling from axon guidance receptors. Cold Spring Harb Perspect Biol 2010; 2: a001941.

76 Whitehead SN, Gangaraju S, Slinn J, Hou ST. Transient and bilateral increase in Neuropilin-1, Fer kinase and collapsin response mediator proteins within membrane rafts following unilateral occlusion of the middle cerebral artery in mouse. Brain Res 2010; 1344: 209-16.

77 Park KS, Martelotto LG, Peifer M, Sos ML, Karnezis AN, Mahjoub MR, et al. A crucial requirement for Hedgehog signaling in small cell lung cancer. Nat Med 2011; 17: 1504-8. 